\title{
Blood flow in a double output centrifugal artificial heart pump as a biventricular assist device
}
D. C. $\operatorname{Sin}^{1}$
A. $\operatorname{Tan}^{2}$
N. Kelson ${ }^{3}$
G. Chadwick ${ }^{4}$

(Received 31 August 2006; revised 8 February 2008)

\begin{abstract}
Recent results show that left ventricular assist devices can extend patient's lives, but may cause right heart failure syndrome; consequently, these patients require a right ventricular assist device. Therefore, biventricular assist device implantation is recommended for long term use. Current development of a biVentricular Assist Device consists of left and right chambers housed in a single unit with different chamber capacity to cater for the differential pressure in left and right outputs. This article proposes a novel biventricular assist device design and estimates the leakage flow. To identify the leakage flow in a biventricular assist device, numerical simulations calculate the velocity profiles and the volumetric flow rates; the results show that the leakage flow rate is dependent on the variation in impeller rotational speed. Computational fluid dynamics simulation is essential to ensure effective and reliable small blood pumps.
\end{abstract}

See http://anziamj.austms.org.au/ojs/index.php/ANZIAMJ/article/view/132 for this article, (c) Austral. Mathematical Soc. 2008. Published February 27, 2008. ISSN 1446-8735 


\section{Contents}

1 Introduction

C950

2 Materials and method

C952

2.1 Initial BVAD design . . . . . . . . . . . . . . C952

2.2 CFD model . . . . . . . . . . . . . . . . . C955

3 Results and discussion $\quad$ C956

3.1 Leakage flow rates . . . . . . . . . . . . . . . C956

3.2 Velocity distribution . . . . . . . . . . . . . C957

4 Conclusion

C958

References

C959

\section{Introduction}

Implantable left ventricular assist devices (LVAD) for use as centrifugal blood pumps are being developed and are seeing clinical use in many institutions. Unfortunately, LVAD implantation may cause liver dysfunction and multiple organ failure due to the high central venous pressure that these devices generate. To prevent this it is imperative to maintain the pressure as low as possible. Early right ventricular assist device (RVAD) implantation decreases right-sided pressure and alleviate liver congestion. However, it is difficult to predict whether the patient requiring a LVAD will also need a RVAD [1]. This prompted current research into the development of an implantable biventricular assist device (BVAD) to deal with longer term bridging to transplantation. The current research focuses on the leakage flow in a BVAD, to assist in this a scaled-up centrifugal ventricular assist devices (VAD) was developed, shown in Figure 1. 


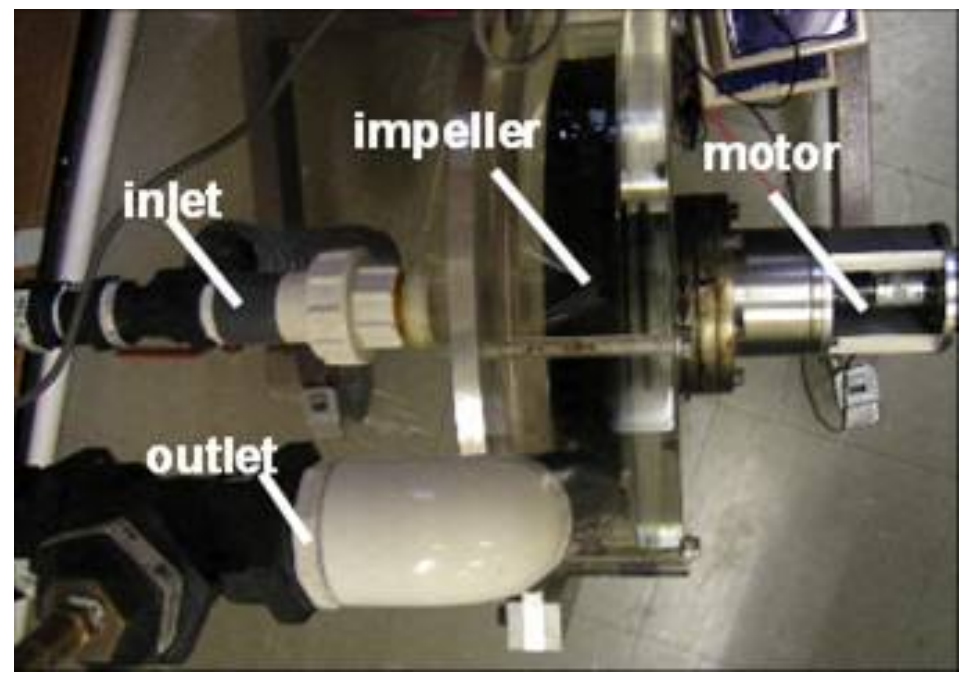

FIGURE 1: Scaled-up centrifugal VAD.

In the development of centrifugal VAD's for medium term use, perhaps longer than six months, it is especially important to eliminate blood stagnation in the clearance gap between the rotating impeller and casing $[2,3]$. Stagnation in this region may lead to thrombus formation. To overcome this problem many centrifugal blood pumps have washout holes located in the impeller to generate circulatory blood flow inside the pump [2, 4]. However, excessive leakage leads to low pump efficiency [5].

Although the flow behaviour in the BVAD can be analysed using the scaled-up VAD shown in Figure 1, the results require excessive time [6]. Alternatively, computational fluid dynamics (CFD) provides an effective method for investigating the geometric parameters of the newly developed pump and possible thrombus formation sites [7].

The objective of the preliminary study is to predict volumetric flow rates and velocity profiles in clearance region of BVAD at different rotational speed and impeller position for the new BVAD design. A functional relationship of 
the leakage flow in terms of the rotational speed helps to predict the leakage flow rate at other operating conditions and also aid in optimising the design.

\section{Materials and method}

\subsection{Initial BVAD design}

The current technique used to address biventricular assistance involves the implantation and operation of two separate pumps. This results in increased size and control complexity arising from the need to control two independent pumps for left and right assistance. The BVAD under development at the QUT in Brisbane, Australia, is of the centrifugal type and is compact in size, its length is $40 \mathrm{~mm}$ and outer diameter is $50 \mathrm{~mm}$. It has a rotational speed of 2,200 rpm which will accommodate a wide rage of pump operation conditions; for example, $5 \mathrm{~L} / \mathrm{min}$ at $100 \mathrm{mmHg}$ and $5 \mathrm{~L} / \mathrm{min}$ at $20 \mathrm{mmHg}$ for LVAD and RVAD, respectively. Figure 2 shows the three dimensional solid model of the design (3D CAD) with its outer casing transparent for clarity. The design includes a LVAD and RVAD impeller positioned on a common rotating hub, thus forming a double sided magnetically and hydrodynamically suspended centrifugal impeller. The vanes of each side are designed to produce the pressure differential and perfusion rates required of the systemic and pulmonary system [8].

In centrifugal blood pump design the impeller suspension system is as important as the impeller design in order to avoid thrombus formation [10]. To obtain low thrombogenicity any BVAD design should avoid areas of low flow where thrombus formation typically occurs by generating suitable flow patterns [9]. The double sided impeller configuration also eliminates areas of low flow or stagnation often found beneath the rotor of conventional single sided centrifugal blood pumps, which significantly reduces the potential for thromboembolic events [8]. 


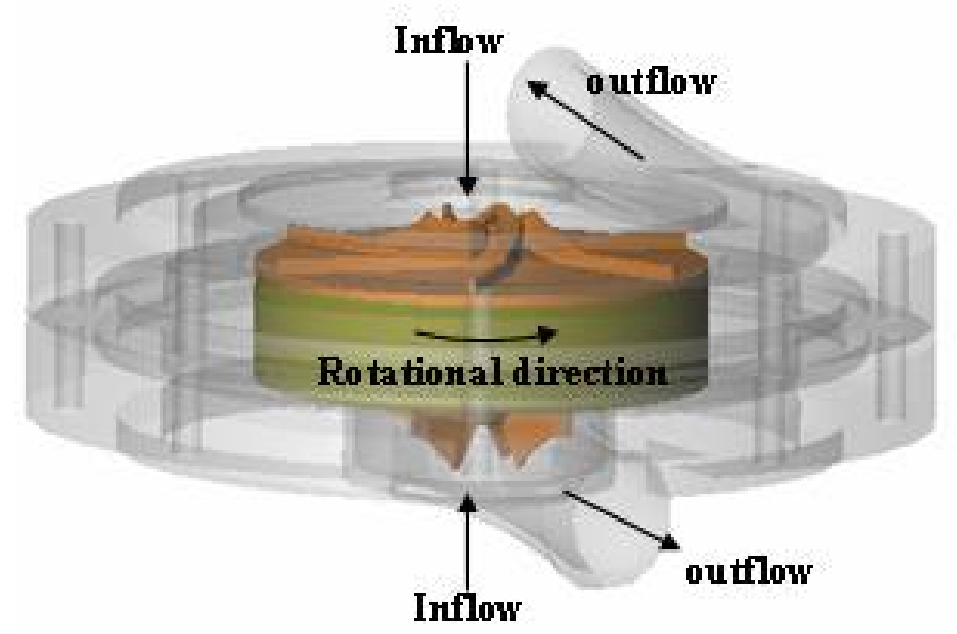

Figure 2: 3D CAD of the BVAD.

This article attempts to model the leakage flow path between the rotating impeller and stationary housing for a new BVAD design. This leakage flow is caused by a pressure difference between the fluid leaving the impeller trailing edge of the LVAD and returning to the RVAD through a designed leakage flow path. Figure 3 shows the schematic view of a BVAD to illustrate the leakage flow path and the pump specifications are shown in Table 1.

The clearance gap between impeller hub and the pump casing is fundamental to the nature of the leakage flow, because a large gap may lead to low thrombus formation. Furthermore, the gap should be kept as small as possible to reduce power consumption and maximise efficiency. The initial radial and axial clearance was selected as $0.5 \mathrm{~mm}$ for the preliminary studies. 
TABLE 1: Design parameters for the BVAD, magnetic suspension blood pump.

\begin{tabular}{lll}
\hline & LVAD & RVAD \\
\hline Design pump head & $100 \mathrm{mmHg}(13.3 \mathrm{kPa})$ & $20 \mathrm{mmHg}(2.66 \mathrm{kPa})$ \\
Design flow rate & $5 \mathrm{~L} / \mathrm{min}$ & $5 \mathrm{~L} / \mathrm{min}$ \\
Impeller diameter & $50 \mathrm{~mm}$ & $50 \mathrm{~mm}$ \\
Design impeller speed & $1,800-2,200$ & $1,800-2,200$ \\
Number of vanes & 6 & 4 \\
Impeller/casing gap & $0.5 \mathrm{~mm}$ & $0.5 \mathrm{~mm}$ \\
\hline
\end{tabular}

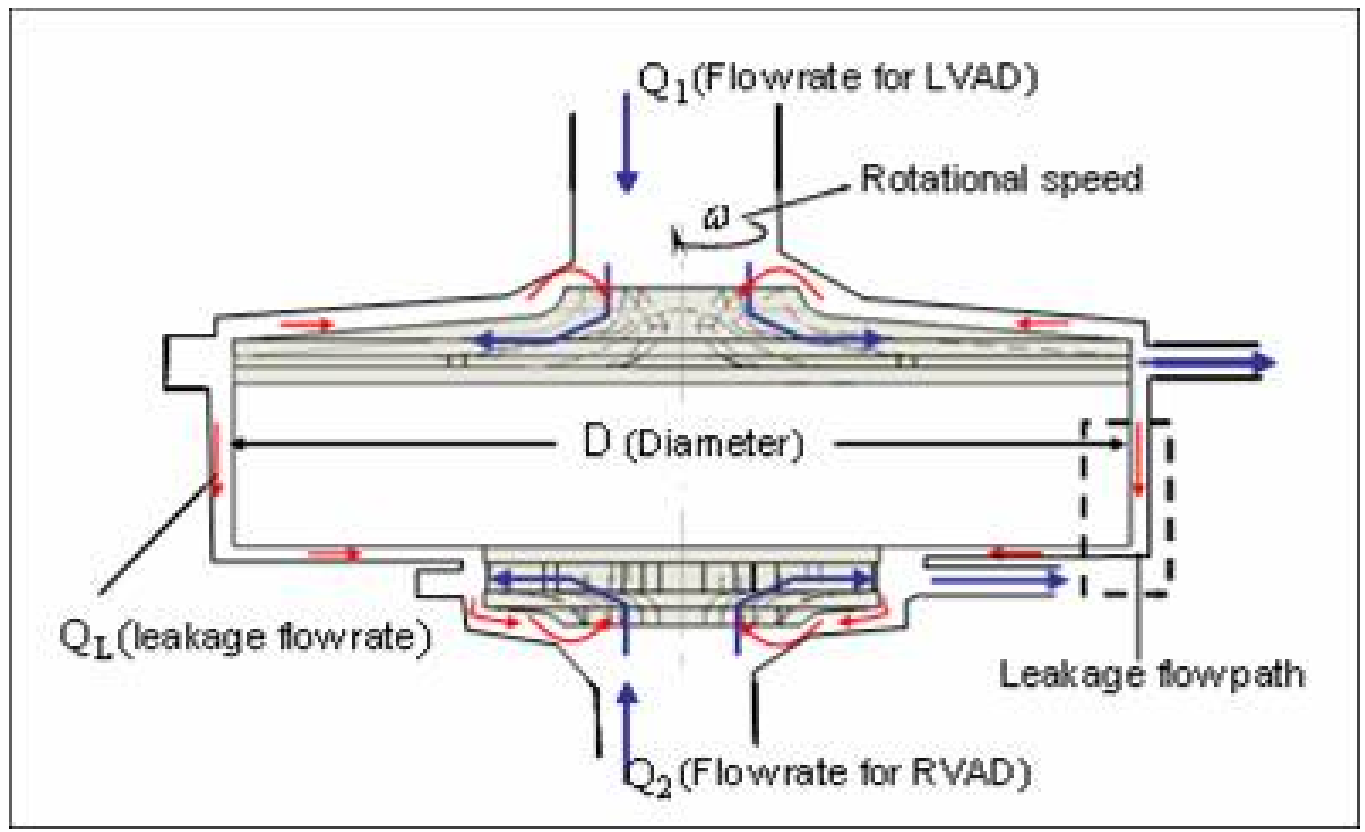

Figure 3: The schematic of the BVAD and the passage of the washout flow. 


\subsection{CFD model}

The schematic Figure 3 shows the geometry for the CFD model, which illustrates the leakage path in the clearance area. The impeller assembly rotates without contacting the pump housing, creating two (axial and radial) clearance regions between the impeller hub and housing. Consequently the CFD model consists of the region around the clearance between the impeller hub and the pump housing. A simplified schematic of the area under investigation and the cylindrical coordinate system are provided in Figure 4. This simplified model consists of a rotating wall of radius $R_{1}$, which has angular velocity and a stationary outer wall of radius $R_{2}$. Hence they are separated by a distance $h$. The pump operating conditions specified for the analysis are a flow rate of $5 \mathrm{~L} / \mathrm{min}$ and supply pressures of 100 and $20 \mathrm{mmHg}$ for the LVAD and RVAD, respectively, yielding a pressure difference of $80 \mathrm{mmHg}$ between the volute of the LVAD and RVAD. The CFD model itself was generated and was discretised using approximately 160000 eight nodded hexahedral elements using GAMBIT software, the pre-processing tool for geometry and mesh generation. For processing and post-processing the commercial CFD code FLUENT was utilised, which produced the required pressure and velocity distributions.

In this study, blood flow is modelled by the momentum and mass conservation equations for an incompressible fluid; the blood itself being treated as a Newtonian fluid with a viscosity of $0.0036 \mathrm{~Pa}$ s and a density of $1059 \mathrm{~kg} / \mathrm{m}^{3}$ [7]. The flow through the pump was assumed to be steady, with a no-slip condition applied to the impeller and casing. The Reynolds Number for this situation was calculated to be $R_{\text {gap }}=863.9$ at rotational speed $2200 \mathrm{rpm}$, much less than the critical number of 1500 , so the flow was assumed to be laminar $[11,12,13]$. In summary, the situation was assumed to be incompressible, steady, laminar flow of a Newtonian fluid. The corresponding steady state $(\partial / \partial t=0)$ governing equations in vector notation for incompressible flow with constant viscosity are

$$
\rho(\vec{v} \cdot \nabla) \vec{v}=-\nabla p+\rho \vec{g}+\nabla \cdot \sigma, \quad \nabla \times \vec{v}=0,
$$




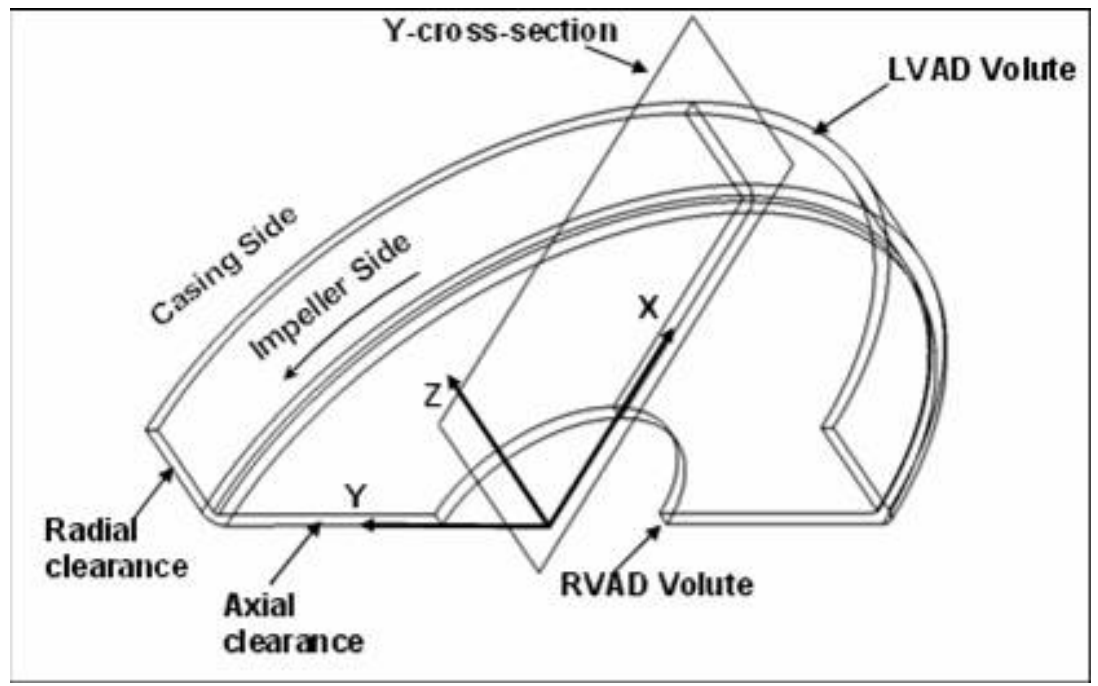

Figure 4: The simplified model of the bvad hub and housing clearance region.

with $\rho$ being the mass density, $\vec{v}$ representing the velocity of the fluid, $P$ pressure, $\rho \vec{g}$ the body force per unit mass and $\sigma$ the stress tensor.

\section{Results and discussion}

\subsection{Leakage flow rates}

The main focus of this study was to assess the effects of variations in impeller rotational speed on leakage flow. Thus volumetric flow rates and velocity profiles in the gap region were analysed at $1800 \mathrm{rpm}, 2000 \mathrm{rpm}$ and $2200 \mathrm{rpm}$. The volumetric leakage flow rates through the leakage flow path are presented in Figure 5, and suggest that flow rate decreases with increasing impeller speed. This effect is probably due to flow reversals that occur at high impeller 


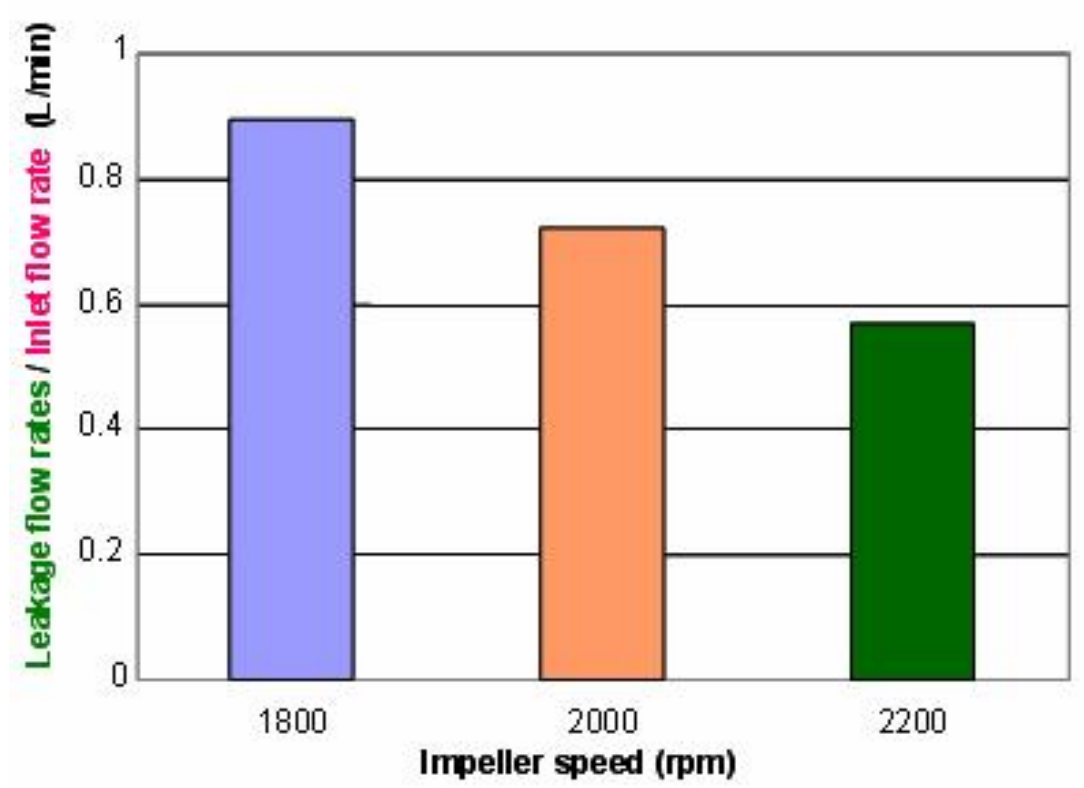

FiguRE 5: Ratio of leakage flow and inlet flow rate.

speed, which effectively block blood flow in flow path.

\subsection{Velocity distribution}

The result of the imposed pressure gradient is a tendency for fluid in the clearance gap to flow from the high pressure LVAD volute to the low pressure RVAD volute. The radial velocity profiles in the axial leakage clearance gap, at varying impeller positions are shown in Figure 6. Pressure dominates flow at the housing and centrifugal effects dominate the flow near the impeller hub, resulting in a blood flow toward the outer radius. As the impeller approaches the left chamber the rotating effect becomes more significant. Consequently, flow reversal by centrifugal force may be generated reducing blood flow and 


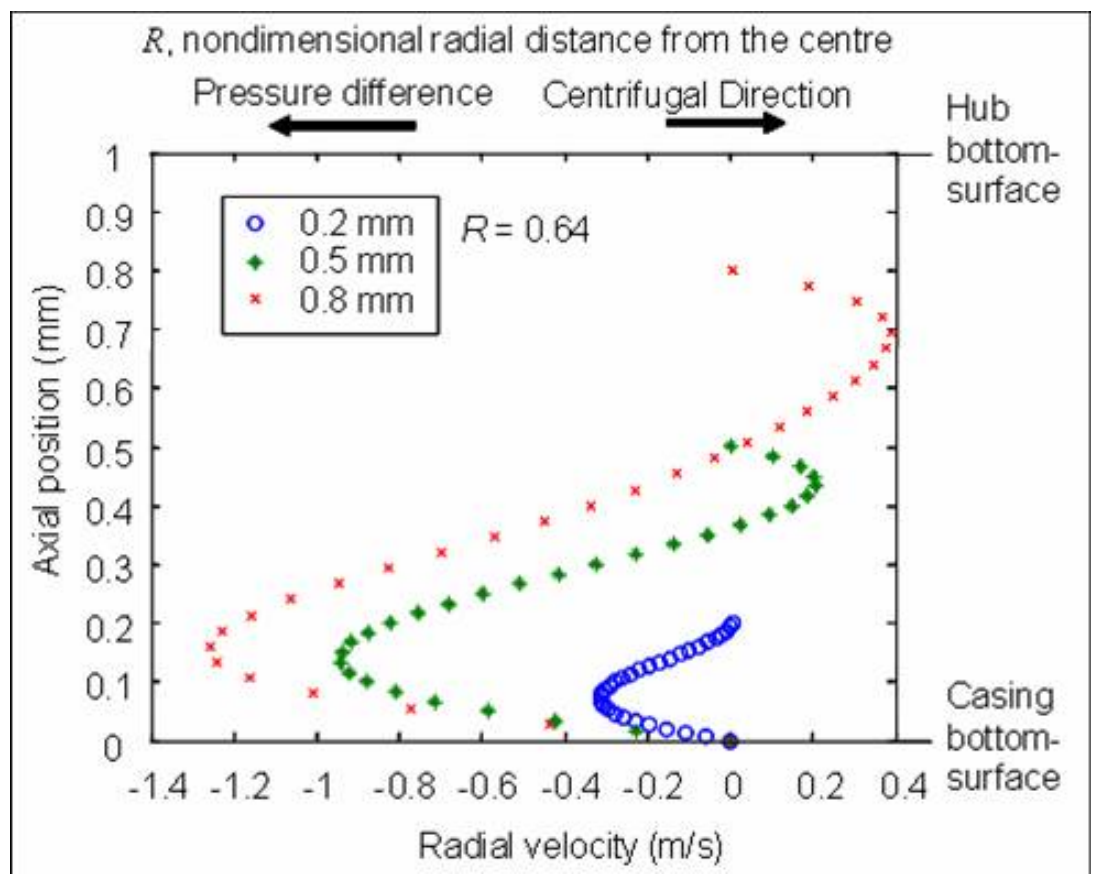

Figure 6: Radial velocity profiles in axial leakage clearance gap.

cause thrombosis.

\section{Conclusion}

To have a good washout it is essential to have relative motion between fluid particles and the rotating hub surface [4]. The most important concern regarding the gap between the impeller hub and the pump housing is that the secondary flow should be enough to avoid blood coagulation or thrombus formation [14]. If, at higher rotational speeds, the inertia forces are large and flow reversal may occur at the rotating hub surface of the BVAD. On the other hand, at lower speed and corresponding inertia forces the pump is 
more efficient in ensuring a better washout [5].

In this article, numerical solutions determine the functional relationship between leakage flow rate and rotational speed. The leakage flow rate is shown to vary almost linearly with the rotational speed. The CFD analysed the secondary flow in terms of velocity profiles and flow rates through the narrow clearance region. The volumetric leakage flow rate was found to be approximately $14.4 \%$ of the inlet flow at $2000 \mathrm{rpm}$. The leakage flow path is designed to provide a washout mechanism that reduces the recirculation duration of the blood in the gap between impeller hub and casing for a double output centrifugal artificial heart pump for use as a BVAD. The present numerical calculations of leakage flow revealed that the leakage flow rate in the BVAD is dependent on the rotational speed and corresponding inertia forces, with lower speed being more efficient in ensuring a better washout. In future studies, CFD predictions will be compared quantitatively to data obtained using PIV measurements.

\section{References}

[1] Y. Nose, K. Nakata, M. Yoshikawa, G. V. Letsou, A. Fujisawa, E. Wolner, and H. Schima, Development of a totally implantable biventricular bypass centrifugal blood pump system, Annals of Thoracic Surgery, 68, pp. 775-9, 1999.

http://ats.ctsnetjournals.org/cgi/content/full/68/2/775 C950

[2] M. Nishida, T. Yamane, and B. Asztalos, Washout Hole Flow Measurement for the Development of a Centrifugal Blood Pump, Artificial Organs, 22, pp. 386-392. doi:10.1046/j.1525-1594.1998.06155.x C951 
[3] Y. Nose, Design and Development Strategy for the Rotary Blood Pump, Artificial Organs, 22, pp. 438-446, 1998.

doi:10.1046/j.1525-1594.1998.06098.x C951

[4] W. K. Chan, T. Akamatsu, and H. D. Li, Analytical Investigation of Leakage Flow in Disk clearance of a Magnetically Suspended Centrifugal Impeller, Artificial Organs, 24, pp. 734-742, 2000. doi:10.1046/j.1525-1594.2000.06507.x C951, C958

[5] W. K. Chan, Wong, Y. W.,, A Review of Leakage Flow in Centrifugal Blood Pump, Arficial Organs, 30, pp. 354-359, 2006. doi:10.1111/j.1525-1594.2006.00225.x C951, C959

[6] M. Nishida and T. Yamane, Geometric Optimization for Non-Thrombogenicity of a Centrifugal Blood Pump through Computational Fluid Dynamic Analysis, JSME International Journal, 47, pp. 1108-1116, 2004. http://sciencelinks.jp/j-east/ article/200506/000020050605A0020366.php C951

[7] k. Kido, H. Hoshi, N. Watanabe, H. Kataoka, K. Ohuchi, J. Asama, T. Shinshi, M. Yoshikawa, and S. Takatani, Computational Fluid Dynamics Analysis of the Pediatric Tiny Centrifugal Blood Pump (TinyPump), Arficial Organs, 30, pp. 392-399, 2006. doi:10.1111/j.1525-1594.2006.00231.x C951, C955

[8] D. L. Timms, Design, Development and Evaluation of Centrifugal Type Ventricular Assist Devices, in Engineering Systems. Brisbane: Queensland University of Technology, 2005, p. 300. C952

[9] C. Gobel, A. Arvand, R. Eilers, O. Marseille, C. Bals, B. Meyns, W. Flameng, G. Rau, and H. Reul, Development of the MEDOS/HIA DeltaStream Extracorporeal Rotary Blood Pump, Artificial Organs, 25, pp. 358-365, 2001. doi:10.1046/j.1525-1594.2001.025005358.x C952 
[10] T. Tsukiya, Y. Taenaka, E. Tatsumi, and H. Takano, Improvement of Washout Flow in a Centrifugal Blood Pump by a Semi-open Impeller, ASAIO Journal, 48, pp. 76-82, 2002. C952

[11] T. Yamane, T. Miyamoto, T. Tajima, K. Yamazaki, H. Clarke, B. Asztalos, M. Nishida, T. Yamane, and T. Kobayashi, Flow Visualization Measurement for Shear Velocity Distribution in the Impeller-Casing Gap of a Centrifugal Blood Pump, JSME International Journal, 42, pp. 621-627, 1999. http://sciencelinks. jp/j-east/article/200003/000020000399A0853032.php C955

[12] T. Ikeda, T. Yamane, T. Orita, and T. Tateishi, A quantitative visualization study of flow in a scaled-up model of a centrifugal blood pump, Artificial Organs, 20, pp. 132-138, 1996. C955

[13] L. Chua, Leakage Flow Rate and Wall Shear Stress Distributions in a Biocentrifugal Ventricular Assist Device, ASAIO Journal, 50, pp. 530-536, 2004. C955

[14] B. Asztalos, T. Yamane, and M. Nishida, Flow Visualization Analysis for Evaluation of Shear and Recirculation in a New Closed-Type, Monopivot Centrifugal Blood Pump, Artificial Organs, 23, pp. 939-946, 1999. doi:10.1046/j.1525-1594.1999.06256.x C958 


\section{Author addresses}

1. D. C. Sin, Institute of Health and Biomedical Innovation, Queensland University of Technology, Brisbane, Australia. mailto:d.sin@qut.edu.au

2. A. Tan, School of Engineering Systems, Queensland University of Technology, Brisbane, Australia.

3. N. Kelson, Division of Technology, Information and Learning Support, Queensland University of Technology, Brisbane, Australia.

4. G. Chadwick, School of Engineering Systems, Queensland University of Technology, Brisbane, Australia. 